\title{
Bilosomes Based Drug Delivery System
}

Keywords: Bilosomes; Vesicular drug delivery; Bile salt, Hepatitis B Oral immunisation

\begin{abstract}
Vesicular camier systems (liposomes \& niosomes) are one of the potential candidates for vaccine delivery by the oral route. But its instability in gastrointestinal environment makes it less applicable to be used for the purpose of oral immunization. This necessitates larger and more frequent doses of antigen for vaccination. Drug delivery system overcomes which a lipid vesicle is containing bile salts (bilosome), which prevents antigen degradation and enhances mucosal penetration. New generation bilosomes are more stable in gastrointestinal tract. This review is sharply focused on comparative overview of liposomes, niosomes and bilosomes. Biolosomes benefits, future perspective, market application characterization and stability of bilosomes.
\end{abstract}

\section{Introduction}

Whilst the prophylactic intramuscular vaccines used to prevent the spread of influenza have been available for 50 years, there is a substantial degree of vaccination failure amongst the elderly $[1,2]$. Only $30-70 \%$ of people aged 65 years or older are successfully immunised against influenza in any one season, compared with a success rate of $70-80 \%$ in younger and healthier individuals $[1,2]$. The problem is further compounded by the fact that more than $40 \%$ of high risk individuals do not receive this vaccine [3]. Therefore, it can be concluded that a vaccine with high efficiency together with the ability to increase patient compliance, would reduce the high death rate associated with this seemingly innocuous virus.

Within the past decade, a number of studies on developing influenza vaccines have been carried out, with most researchers investigating parenteral or nasal immunisation strategies. However, despite the recent shift of attention towards intranasal administration and oral vaccination is still considered the best approach to increase patient compliance. Several oral delivery systems have been extensively studied, including liposomes and the recent innovation, the bilosome [4].

Bilosomes consist of deoxycholic acid incorporated into the membrane of niosomes [4]. Bile salts are commonly used as penetration enhancers by the pharmaceutical industry and promote oral bio-availability $[3,5]$. In the past, larger and more frequent oral antigen doses were given to overcome the digestive barrier $[3,6]$. This in turn led to problems such as the induction of oral tolerance. Another advantage of the bilosome is they are produced from naturally occurring lipids making them biocompatible. The bilosome components have also been shown to possess inherent adjuvant properties when associated with antigen [4].

\section{What are Bilosomes}

Bilosomes are specialised delivery vehicles which protect vaccines from being broken down in the stomach, thereby enabling the oral
Journal of

Chemistry \& Applications

Ramchandra N. Chilkwar ${ }^{1}$, Basavaraj K. Nanjwade $^{2 *}$, Moftah S. Nwaji ${ }^{4}$, Salah M. Idris ${ }^{5}$ and Anas S. Mohamied ${ }^{5}$

${ }^{1}$ Department of Quality Assurance, Remidex Pharma Pvt Ltd., 2nd Stage, Peenya Industrial Area, Bengaluru-560058, Karnataka, India ${ }^{2}$ Department of Pharmaceutics, Faculty of Pharmacy, Omer AlMukhtar University, Tobruk, P. O. Box 919, Libya

${ }^{3}$ Department of Pharmaceutical Microbiology, Faculty of Pharmacy, Omer Al-Mukhtar University, Tobruk, P. O. Box 919, Libya

${ }^{4}$ Department of Pharmaceutical Chemistry, Faculty of Pharmacy, Omer Al-Mukhtar University, Tobruk, P. O. Box 919, Libya

${ }^{5}$ Department of Pharmaceutics, Faculty of Pharmacy, Omer AlMukhtar University, Al-Bayda, P. O. Box 919, Libya

\section{Address for Correspondence}

Basavaraj K. Nanjwade, Department of Pharmaceutics, Faculty of Pharmacy, Omer Al-Mukhtar University, Tobruk, P. O. 919, Libya, Tel: 0218944828793; E-mail: nanjwadebk@gmail.com

Copyright: @ 2015 Chilkwar RN, et al. This is an open access article distributed under the Creative Commons Attribution License, which permits unrestricted use, distribution, and reproduction in any medium, provided the original work is properly cited.

Submission: 07 May 2015

Accepted: 22 May 2015

Published: 26 May 2015

Reviewed \& Approved by: Dr. Xing Wang, Assistant Professor, Department of Chemistry and Chemical Biology, Rensselaer Polytechnic Institute, New York

delivery of vaccines as an alternative to administering treatment by injection.

In 2004, Mann et al., developed non-ionic surfactant vesicle (NISV) having liposome like structures and stabilized them with bile salts for the oral delivery of vaccines. These were called bilosome, bilosomes differ from the liposomes and niosomes in term of their composition, chemical stability and storage conditions (Table 1). In order to avoid the problems during GI transit, bilosomes were developed which not only prevented antigens from degradation, but also enhanced mucosal penetration. Bilosome based vaccine produced both systemic as well as mucosal immune response which was equivalent to immune response produced by subcutaneous route [7].

Table 1: Comparative overview of liposomes, niosomes and bilosomes.

\begin{tabular}{|c|c|c|c|}
\hline Parameter & Liposomes & Niosomes & Bilosomes \\
\hline Composition & $\begin{array}{l}\text { Natural } \\
\text { Phospholipids, } \\
\text { cholesterol }\end{array}$ & $\begin{array}{l}\text { Non-ionic } \\
\text { surfactant with } \\
\text { cholesterol }\end{array}$ & $\begin{array}{l}\text { Non-ionic } \\
\text { surfactant and } \\
\text { bile salt }\end{array}$ \\
\hline Chemical stability & $\begin{array}{l}\text { Phospholipids } \\
\text { undergo the } \\
\text { oxidative } \\
\text { degradation }\end{array}$ & Stable & Stable \\
\hline GIT stability & Unstable & Unstable & Stable \\
\hline Antigen dose & $\begin{array}{l}\text { Comparatively } \\
\text { high }\end{array}$ & $\begin{array}{l}\text { Comparatively } \\
\text { high }\end{array}$ & Comparatively low \\
\hline $\begin{array}{l}\text { Storage and } \\
\text { handling } \\
\text { condition }\end{array}$ & $\begin{array}{l}\text { Required special } \\
\text { conditions (liquid } \\
\text { nitrogen } \\
\text { storage) }\end{array}$ & $\begin{array}{l}\text { Do not required } \\
\text { special conditions }\end{array}$ & $\begin{array}{l}\text { Do not required } \\
\text { special conditions }\end{array}$ \\
\hline
\end{tabular}


Citation: Chilkwar RN, Nanjwade BK, Nwaji MS, Idris SM, Mohamied AS. Bilosomes Based Drug Delivery System. J Chem Applications. 2015;2(1): 5.

Two years later, new bilosome based vaccine formulation i.e. tetanus toxoid using vesicles containing bile salts for oral delivery were studied [8]. Nanotoxicity and adjuvant effect of NISV were established [9]. The ability of orally administered bilosome based vaccines to induce systemic immune responses in mice, using a standard antigen (bovine serum albumin), a synthetic measles peptide and an influenza sub-unit vaccine were studied. Immune response of above vaccine formulations was increased by incorporating bile salts (in particular deoxycholate). Bilosome based measles peptide vaccine stimulated a specific cell mediated response. Orally administered bilosome based influenza sub-unit vaccine induced systemic immune response same as that produced by parenterally administered vaccine containing the same quantity of antigen [10]. Bilosomes containing bovine serum albumin (BSA) as a model antigen and its conjugate with cholera toxin $B$ subunit (CTB) were prepared. Immune response produced by a single oral dose of cholera toxin B (CTB) conjugated bilosome was almost equivalent to immune response, produced by parenteral administration of antigen with Freund's complete adjuvant (FCA).

Despite this similarity in the immune response, bilosomes has advantages like oral administration is convenient and devoid of any adverse effects as compare to parenteral administration of FCA [11]. HBsAg loaded bilosomes, when given orally, produced high systemic as well as mucosal immune response. Orally administrated five times dose of HBsAg loaded bilosomes was found to produce same systemic immune response as that of intra-muscularly administrated alum adsorbed HBsAg vaccine [12]. Other studies carried out using bilosomes are listed in (Table 2)

\section{Benefits}

- Bilosomes allow small quantities of antigen to be effective and also increase the efficacy of antigen which are weak when injected.
- Bilosomes do not require the use of live pathogens, making them a safe and effective alternative to traditional vaccines.

- This non-invasive system offers advantages in terms of user acceptance and compliance.

- The conventional injection method suffers from high relative costs and requires trained persons to administer the treatment.

- Less toxicity envelope suitable for a wide range of therapeutic agents.

- Immune response could be manipulated through control of the size of the carrying vesicle.

- Bilosomes removes the cold-chain requirement for preparations such as vaccine.

- Bilosomes provides new delivery system improving patient compliance, its ease of administration and potentially providing extended patent life.

The bilosomes patent represents a major step forward in vaccine technology by avoiding common problems associated with injections and increasing the efficacy of vaccines.

\section{Bilosomes using Oral Immunization against Hepatitis B Virus}

Hepatitis B is a type of stern and deadly viral disease caused by hepatitis $B$ virus (HBV). It is a partially double-stranded DNA virus of the Hepadnaviridae family which includes related viruses responsible for liver injury in animals [15]. HBV is carried in blood and in other body fluids including tears, saliva, semen and vaginal secretions and can be transmitted from person to person by a variety of means.

In some studies it was concluded that after its acute infection,

Table 2: Bilosomes based vaccine formulations

\begin{tabular}{|c|c|c|c|c|}
\hline Bilosomes Composition/Type & Vaccine/Antigen & ROA & Inference & Ref. \\
\hline $\begin{array}{l}\text { 1-Monopalmitoyl glycerol, cholesterol } \\
\text { and dicetyl phosphate, deoxycholic acid }\end{array}$ & Influenza vaccine & Oral & $\begin{array}{l}\text { Significant lgG1 titres were induced when the protein } \\
\text { loading was doubled from } 15 \text { to } 30 \mu \mathrm{g} \text { and was equivalent } \\
\text { to antigen administration by the subcutaneous route. } \\
\text { No IgG2a was induced, indicating the generation of a } \\
\text { Th2 response. Significant mucosal IgA levels were also } \\
\text { observed }\end{array}$ & [7] \\
\hline $\begin{array}{l}\text { Non-ionic surfactant vesicles, deoxycholic } \\
\text { Acid }\end{array}$ & $\begin{array}{l}\text { Tetanus Toxoid } \\
\text { vaccine }\end{array}$ & Oral & $\begin{array}{l}\text { Entrapped TT, caused a rise in the numbers of IgA positive } \\
\text { plasma cells observed in the first } 6 \text { in of the small intestine }\end{array}$ & [8] \\
\hline $\begin{array}{l}\text { Non-ionic surfactant vesicles, deoxycholic } \\
\text { acid }\end{array}$ & Influenza subunit & Oral & $\begin{array}{l}\text { The present study demonstrated that oral administration } \\
\text { of bilosomes incorporating the influenza sub-unit vaccine } \\
\text { could induce a potent antibody response as the parenterally } \\
\text { administered vaccine containing the same quantity of } \\
\text { antigen }\end{array}$ & [10] \\
\hline $\begin{array}{l}\text { Sorbitan tristearate, cholesterol, DPPEMCC } \\
\text { and CTB }\end{array}$ & $\begin{array}{l}\text { Bovine serum } \\
\text { albumin vaccine }\end{array}$ & Oral & $\begin{array}{l}\text { In contrast to FCA, oral administration of bilosomes is } \\
\text { convenient } \\
\text { and devoid of any adverse effects that are observed with } \\
\text { parenteral } \\
\text { administration of FCA }\end{array}$ & [11] \\
\hline $\begin{array}{l}\text { Sorbitan tristearate, cholesterol, dicetyl } \\
\text { phosphate,sodium deoxycholate }\end{array}$ & $\begin{array}{l}\text { Hepatitis B } \\
\text { Vaccine }\end{array}$ & Oral & $\begin{array}{l}\text { HBsAg loaded bilosomes produced both systemic as well } \\
\text { as mucosal antibody responses upon oral administration }\end{array}$ & [12] \\
\hline $\begin{array}{l}\text { Non-ionic surfactant vesicles, deoxycholic } \\
\text { Acid }\end{array}$ & $\begin{array}{l}\text { Influenza A } \\
\text { Antigen }\end{array}$ & Oral & $\begin{array}{l}\text { Physically modification (size) of nanocarriers can be used } \\
\text { to manipulate } \\
\text { immune responses }\end{array}$ & [13] \\
\hline
\end{tabular}

DPPE- Dipalmitoyl phosphatidyl ethanoloamine; SMCC- Succinimidyl-4-N-maleimidomethyl-cyclohexane-1-carboxylate; CTB- Cholera toxin B subunit; FCA - Freund's complete adjuvant; HBsAg- Hepatitis B surface antigen 
Citation: Chilkwar RN, Nanjwade BK, Nwaji MS, Idris SM, Mohamied AS. Bilosomes Based Drug Delivery System. J Chem Applications. 2015;2(1): 5.

ISSN: $2380-5021$

between 1 and $10 \%$ of healthy adults and $30-90 \%$ of infected babies become chronic carriers and on later stages they are at high risk of life-threatening diseases such as cirrhosis and primary hepatocellular carcinoma (HCC). Worldwide, atleast one third of the world population have been infected with HBV, over $6 \%$ of the world population are chronic carriers and approximately 620,000 people die every year from acute and chronic HBV infection [16]. Globally approximately 4.5 million new HBV infections occur each year of which a quarter progresses to liver disease $[17,18]$.

Immunization is the most successful measure to diminish the global prevalence of hepatitis B. Vaccination is the most important and economically attractive option for healthcare intervention both in terms of cost-effectiveness and benefit-cost ratios. The present concept of vaccination is based on invasive parenteral method which is not completely effective against number of diseases [19]. These traditional needle-based vaccination methods suffer from various drawbacks, like the need for trained personnel to administer vaccines, patient inconvenience and the associated risk of needle-borne infections (AIDS, hepatitis, etc.) due to the use of contaminated needles [20]. The need for trained medical personnel elevated the cost of administration and confined the use of parenteral vaccines in isolated and interior areas. Further, parenterally administered vaccines mainly stimulate a systemic response and antibodies generated in this manner do not always reach to the mucosal surfaces, which is the predominant entry site for most infectious pathogens [21].

These concerns about injectable vaccines are absent in the use of mucosal vaccines. One of needle-free mode of immunization is the oral mucosal immunization that can be commonly and successfully exploited. Features of oral mucosal vaccines i.e. Generation of both mucosal and systemic immunity and better compliance validate this route as effective prophylactic gadget in health care [22]. Oral route is also associated with some major problems including low oral bioavailability of protein related formulations, particularly vaccines. So, to enhance the response and to deliver the vaccine via oral route, suitable delivery vehicle is needed [23].
Several delivery systems which are safe and non toxic and derivatives of commonly used adjuvant have been explored to overcome the above mentioned problems related to delivery of vaccines. They include emulsions, dendrimers, polymeric microand nanoparticles, lipid nanoparticles, lipid based vesicles such as liposomes, niosomes, bile salt containing vesicles (bilosomes) and other phospholipids based vesicular constructs and immunestimulating complexes (ISCOMS). These delivery systems have been shown to protect antigens from degradation in gastrointestinal tract. Particulate systems like nanoparticles of similar size and dimension of the pathogens are efficiently taken up by $\mathrm{M}$ cells and hence deliver associated antigen into the antigen presenting cells to provoke strong immune response [24]. Lipid based carriers have also been investigated extensively in the past decades as they resemble with biological membranes and may serve as potential drug and peptide carriers.

The susceptibility of conventional vesicles (both liposomes and niosomes) to bile salt caused dissolution and enzymatic degradation in the gastrointestinal tract remains as the main barrier for their effective oral delivery and led to the development of modified versions of vesicles [25]. Incorporation of bile salts in niosomal formulation could stabilize the membrane against the detrimental effects of bile acids in GI tract [26]. These bile salt stabilized vesicles referred to as "Bilosomes". These allow small quantities of antigen to be effective and both cellular and humoral immune responses can be induced [27]. Further, mannan coating on the novel carrier system can further stabilize the vesicles in gastrointestinal environment as well as can act as a targeting ligand for mannose receptors expressed on macrophages and dendritic cells which are the major antigen presenting cells present in the vicinity of Peyer's patches $[28,29]$.

\section{Characterization of Bilosomes}

Bilosomes characterized for their shape and size, a transmission electron microscope (Philips CM-10, Netherlands) used for morphological examination of the bilosomes. A photon correlation spectroscopy used for determination of mean particle size. Particle

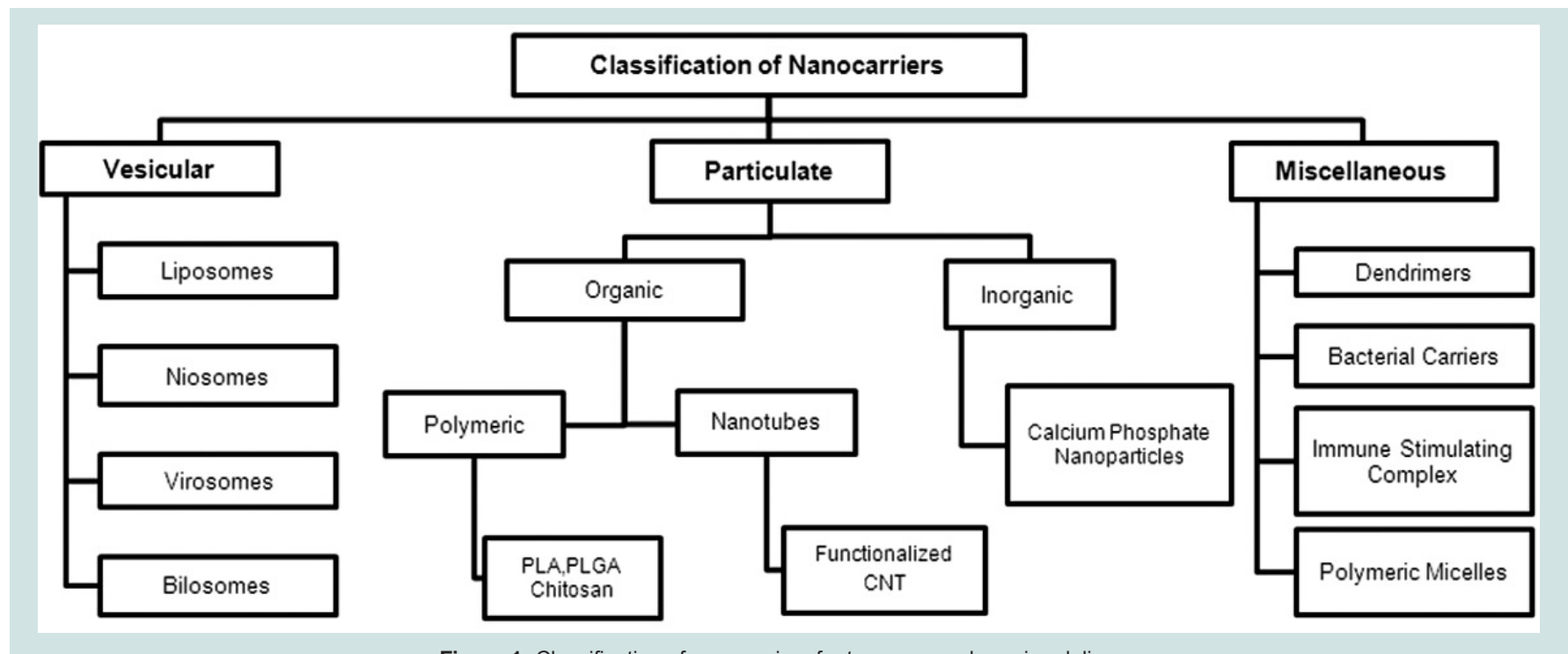

Figure 1: Classification of nanocarriers for transmucosal vaccine delivery. 
Citation: Chilkwar RN, Nanjwade BK, Nwaji MS, Idris SM, Mohamied AS. Bilosomes Based Drug Delivery System. J Chem Applications. 2015;2(1): 5.

ISSN: 2380-5021

size analyzer used to carry out vesicle size and size distribution studies [30,31].

\section{Stability Studies of Vesicles in Simulated Gastrointestinal Fluid}

Stability determination of coated and uncoated bilosomes can be done in simulated gastric fluid (SGF) and simulated intestinal fluid (SIF) in comparison with SGF (pH 1.2) and SIF (pH 7.5) with continuous shaking on wrist action shaker for 2 hour Residual antigen content and number of intact vesicles was then determined [30,31]

\section{Conclusion and Future Perspectives}

Vesicular drug delivery systems are emerging with the diverse application in pharmaceuticals, cosmetics and cosmeceuticals and food industries. The delivery of drug directly to the site of infection and it's leading to reduction of drug toxicity with no adverse effects. It also reduces the cost of therapy by imparting better biopharmaceutical properties to the drug, resulting in improved bioavailability and especially in case of poorly soluble drugs. Oral administration remains the favoured method of drug delivery by patients and drug to be successfully absorbed by the body. It requires the active molecule to transit through the stomach and then to be transferred across the intestinal wall to the bloodstream. For a majority of vaccines and biologic therapeutics this is not an option due to a $1 \%$ uptake of the dose given. Approximately $1 / 3$ of small molecule drugs also face oral absorption challenges many of these are focussed on CNS targets.

\section{Technology}

Scientists at Strathclyde have developed bilosomes and bile salt stabilised vesicles that act as an envelope to protect their contents from the harsh environment of the gut enabling oral administration. The system was well tolerated in vivo toxicology studies.

\section{Markets and Applications}

Bilosomes has been reported as an effective in the delivery of vaccines (currently under license) and can be applied to the delivery of biological therapeutics and traditional small molecule drugs.

\section{Licensing and Development}

The technology is covered by granted patent (US 5,876,721 and EP 0722341B1) currently under license. Patents relating to small molecule and biological therapeutic encapsulation are in preparation [32].

\section{References}

1. Sambhara S, Kurichh A, Miranda R, Tamane A, Arpino R, et al. (1998) Enhanced immune responses and resistance against infection in aged mice conferred by Flu-ISCOMs vaccine correlate with up-regulation of costimulatory molecule CD86. Vaccine 16: 1698-1704.

2. Nichol KL (2003) The efficacy, effectiveness and cost-effectiveness of inactivated influenza virus vaccines. Vaccine 21: 1769-1775.

3. Sizer PJH (1997) Towards an oral influenza vaccine. Trends Biotechnol 15: 282-285.

4. Conacher M, Alexander J, Brewer JM (2001) Oral immunisation with peptide and protein antigens by formulation in lipid vesicles incorporating bile salts (bilosomes). Vaccine 19: 2965-2974.

5. Aungst BJ, Saitoh H, Burcham DL, Huang SM, Mousa A, et al. (1996)
Enhancement of the intestinal absorption of peptides and non-peptides. $J$ Control Release 41: 19-31.

6. Lavelle EC, Sharif S, Thomas NM, Holland J, Davis SS (1995) The importance of gastrointestinal uptake of particles in the design of oral delivery systems. Adv Drug Delivery Rev 18: 5-22.

7. Mann JF, Ferro VA, Mullen AB, Tetley L, Mullen M, et al. (2004) Optimisation of a lipid based oral delivery system containing A/Panama influenza haemagglutinin. Vaccine 22: 2425-2429.

8. Mann JF, Scales HE, Shakir E, Alexander J, Carter KC, et al. (2006) Oral delivery of tetanus toxoid using vesicles containing bile salts (bilosomes) induces significant systemic and mucosal immunity. Methods 38: 90-95.

9. Senior K (2001) Bilosomes: the answer to oral vaccine delivery? Drug Discov Today 6: 1031-1032.

10. Conacher M, Alexander J, Brewer JM (2001) Oral immunisation with peptide and protein antigens by formulation in lipid vesicles incorporating bile salts (bilosomes). Vaccine 19: 2965-2974.

11. Singh P, Prabakaran D, Jain S, Mishra V, Jaganathan KS, et al. (2004) Cholera toxin $B$ subunit conjugated bile salt stabilized vesicles (bilosomes) for oral immunization. Int J Pharm 278: 379-390.

12. Shukla A, Khatri K, Gupta PN, Goyal AK, Mehta A, et al. (2008) Ora immunization against hepatitis $B$ using bile salt stabilized vesicles (bilosomes). J Pharm Pharm Sci 11: 59-66.

13. Mann JF, Shakir E, Carter KC, Mullen AB, Alexander J, et al. (2009) Lipid vesicle size of an oral influenza vaccine delivery vehicle influences the Th1/ Th2 bias in the immune response and protection against infection. Vaccine 27: 3643-3649.

14. http://www.strath.ac.uk/media/ps/rkes/enterprisematters/media_101328_ en.pdf

15. Zanetti AR, Damme PV, Shoval D (2008) The global impact of vaccination against Hepatitis B: A historical overview. Vaccine 26: 6266-6273.

16. Kane MA (1996) Global status of hepatitis B immunisation. Lancet 348: 696

17. Lee WM (1997) Hepatitis B virus infection. N Engl Med 337: 1733-1745.

18. Goldstein ST, Zhou F, Hadler SC, Bell BP, Mast EE, et al. (2005) A mathematical model to estimate global hepatitis B disease burden and vaccination impact. Int J Epidemiol 34: 1329-1339.

19. Aziz MA, Midha S, Waheed SM, Bhatnagar R (2007) Oral vaccines: new needs, new possibilities. Bioessays 29: 591-604.

20. Ryan EJ, Daly LM, Mills KH (2001) Immunomodulators and delivery systems for vaccination by mucosal routes. Trends Biotechnol 19: 293-304.

21. Nugent J, Po AL, Scott EM (1998) Design and delivery of non-parentera vaccines. J Clin Pharm Ther 23: 257-285.

22. Arora D, Goyal AK, Paliwal SR, Khurana B, Vyas SP (2010) Oral mucosa immunization: recent advancement and future prospects. Current Immunology Reviews 6: 234-259.

23. Jain AK, Goyal AK, Gupta PN, Khatri K, Mishra N, et al. (2009) Synthesis, characterization and evaluation of novel triblock copolymer based nanoparticles for vaccine delivery against hepatitis B. J Control Release 136 161-169.

24. Galindo-Rodriguez SA, Allemann E, Fessi H, Doelker E (2005) Polymeric nanoparticles for oral delivery of drugs and vaccines: A critical evaluation of in vivo studies. Crit Rev Ther Drug Carrier Syst 22: 419-464.

25. Katare R, Gupta PN, Mahor S (2006) Development of polysaccharide-capped niosomes for oral immunization of tetanus toxoid. J Drug Deliv Sci Technol 16: 167-172.

26. Mann JFS, Scales HE, Shakir E (2006) Oral delivery of tetanus toxoid using vesicles containing bile salts (bilosomes) induces significant systemic and mucosal immunity. Methods 38: 90-95.

27. Conacher M, Alexander J, Brewer JM (2001) Oral immunization with peptide and protein antigens by formulation in lipid vesicles incorporating bile salts 
Citation: Chilkwar RN, Nanjwade BK, Nwaji MS, Idris SM, Mohamied AS. Bilosomes Based Drug Delivery System. J Chem Applications. 2015;2(1): 5.

ISSN: $2380-5021$

(bilosomes). Vaccine 19: 2965-2974.

28. Jain S, Singh P, Mishra V, Vyas SP (2005) Mannosylated niosomes as adjuvant-carrier system for oral genetic immunization against Hepatitis $B$. Immunol Lett 101: 41-49.

29. Kelsall BL, Strober W (1996) The role of dendritic cells in antigen processing in the Peyer's patch. Ann N Y Acad Sci 778: 47-54.

30. Arora D, Khurana B, Kumar MS, Vyas SP (2011) Oral immunization against hepatitis B virus using mannosylated bilosomes. Int J Rec Adv Pharm Res 1: 45-51.

31. Shukla A, Khatri K, Gupta PN, Goyal AK, Mehta A, et al. (2008) Oral immunization against hepatitis $B$ using bile salt stabilized vesicles (bilosomes). J Pharm Pharm Sci 11: 59-66.

32. h t t p : / / w w w. st rat h.a c.uk/rkes/f/y/ bilosomesnovelvehiclesfororaldeliveryofdrugs/ 